\title{
INNOVATION CLUSTER AS A MECHANISM FOR ENSURING THE ENTERPRISES INTERACTION IN THE INNOVATION SPHERE
}

\author{
Ihor Kuksa ${ }^{1}$, Iryna Shtuler ${ }^{2}$, Olga Orlova-Kurilova ${ }^{3}$, ${ }^{*}$ Iryna Hnatenko ${ }^{4}$, \\ Viktoriia Rubezhanska ${ }^{5}$
}

\author{
${ }^{1}$ Prof. Dr Sc. (Ekon). Luhansk National Agrarian University. Bolshaya Sadova str. 2. 92702. \\ Starobilsk. Ukraine. Tel. +380506475207. E-mail igor.kuksa.23@gmail.com \\ ${ }^{2}$ Assoc. Prof. PhD of Econ. National Academy of Management. Ushynskogo str. 15. 03151. \\ Kyiv. Ukraine. Tel. +380507633413. E-mail shkirka2002@ukr.net \\ ${ }^{3}$ Assoc. Prof. PhD of Econ. Luhansk National Agrarian University. Bolshaya Sadova str. 2. \\ 92702. Starobilsk. Ukraine. Tel.+380506210239. E-mail orlovakur73@gmail.com \\ ${ }^{4}$ Assoc. Prof. PhD of Econ. Kyiv National University of Technologies and Design. \\ Nemyrovycha-Danchenka Street 2.01011. Kyiv. Ukraine. \\ Tel.+380661076939, E-mailq17208@ukr.net \\ ${ }^{5}$ PhD of Econ. Luhansk Taras Shevchenko National University. Gogol str. 1. 92700. \\ Starobilsk.Ukraine.Tel.+380953081789.E-mail rubezhiik@gmail.com
}

Received 1410 2019; accepted 20122019

International experience in managing the innovation development of national economies demonstrates the synthesis of scientific, industrial, economic and social policies in the form of specific entities - innovation clusters in order to create and active use of innovations. In this regard, ensuring the effective functioning and development of innovative clusters that positively affect the competitiveness of the economy of any country in the world is of particular relevance. The aim of the study is to develop a methodology for assessing the effectiveness of the enterprises interaction in the innovation cluster for further planning of measures to improve its functioning. To achieve this goal, the following methods of scientific research were used: the method of comparison and synthesis; the econometric method; abstract-logical method; the graphic method. The methodology developed in the course of the study should be used in forming the directions of the development strategy of new cluster members, in adjusting the existing strategy to the acting clusters of enterprises and in developing measures aimed at increasing the effectiveness of their interaction.

Key words: innovation cluster, state support of innovation cluster, competitiveness, enterprise-participant of cluster, efficiency of interconnections.

JEL Codes M21, O10, R38

\section{Introduction}

In a contemporary context globalization processes dictate the need for unification and the benefits of regularities homogeneity in different conditions.

Copyright (C) 2019 The Authors. Published by Vytautas Magnus University. This is an open-access article distributed under the terms of the Creative Commons Attribution-NonCommercial 4.0 (CC BY-NC 4.0) license, which permits unrestricted use, distribution, and reproduction in any medium, provided the original author and source are credited. The material cannot be used for commercial purposes.

\footnotetext{
* Corresponding author
} 
However, it is the diversity of national characteristics and the specific conditions in each country that provides the necessary differentiation of the forms of general regularities manifestation and a kind of national model's competition of doing business (Kuksa, Hnatenko, Orlova-Kurilova, Moisieieva, Rubezhanska, 2019). International experience in managing the innovation and scientific and technological development of national economies demonstrates the synthesis of scientific, industrial, economic and social policies in the form of specific entities called the "innovation clusters" in order to create and maintain an environment conducive to the creation and active use of innovations. The specificity of the cluster is obtaining by the organizations belonging to it the synergistic effect which is expressed in increasing the competitiveness of the whole system compared with individual economic entities.

At the same time, the competitiveness of the modern economy depends not only on technical achievements, inventions, knowledge creation, but also on organizational changes that promote the commercialization of the results of scientific and technical developments, as well as marketing innovations. In this connection, ensuring the effective functioning and development of innovative clusters in order to achieve a sufficient level of the economy competitiveness of any country in the world becomes especially relevant. In this case, the significant importance is obtained by the determining the effectiveness of the enterprises interaction in the innovation cluster, which provides the overall performance of the cluster.

The research of various aspects of the formation and functioning of innovative clusters, their influence on the world economic development is devoted to the scientific work of many scientists. Thus, Sternberg, Kiese, Stockinger (2010) compared the cluster policy of North Carolina and Bavaria located in multilevel governance systems of countries in which the state level interacts with federal and local policies.

The findings of the study authors emphasize the importance of institutional contexts that need to be taken into account when adapting cluster policies to specific circumstances.Zaenchkovsky (2018) conducted a study on the practice of implementing a cluster approach in industry, in particular in the EU, the impact of clusters on competitiveness indicators of cluster localization territories, as well as stimulating the growth and realization of the country's scientific and industrial potential as a whole. In the scientific work of Lindqvist, Ketels, Solvell (2003) there was carried out a detailed analysis of the activities of 250 innovative clusters from around the world and proposed a new model for assessing the effectiveness of the cluster (Cluster Initiative Performance Model).

In the article of Nishimura, Okamuro (2011) there were examined the effects of the "Industrial Cluster Project" in Japan on the performance of R \& D participants and based on the data of 229 firms the conditions necessary for the efficient organization of cluster policy are determined. Foley, Freihaut, Hallacher, Knapp (2011) considered features of the functioning of the Great Philadelphia innovation 
cluster (GPIC), substantiated its significance for the national economic system of the United States.

Feser, Renski, Goldstein (2008) investigated the relationship between industry clusters and regional economic outcomes; provided the evidence that clusterization is associated with the formation of a new business for individual industries, but not with the employment growth. A research work of Spencer, Vinodrai, Gertler, Wolfe (2010) is devoted to the development of a new cluster methodology that can be used to verify the relationship between geographical clusterization of economic activity and high industrial productivity and regional competitiveness.

Rosenfeld (2005) discussed the process of clusters evolution from networks, described the main strategies of cluster development and their application in practice. An article of Enright (2010) focuses on a number of studies on supporting innovative clusters within the OECD, and in addition highlights the issues associated with evaluating these initiatives and available evidence of their results. Kukalis (2010) carried out the comparative analysis of financial indicators of clustered and nonclustered enterprises of semiconductor and pharmaceutical industry at different stages of the life cycle of industries. Rauch, Doorn, Hulsink (2014) considered the cases of increasing by the business clusters of the performance of the enterprises that are part of them.

Scientific work of Tessitore, Daddi, Frey (2012) is devoted to the study of the relationship between environmental innovations and the competitiveness of enterprises in the process of cluster functioning. The authors found that only in some cases there is a specified link. An article of Rosa (1998) presents the results of the conducted case studies of life stories and business genealogies of ordinary entrepreneurs possessing highly developed businesses in Scotland.

The author reveals a variety of experience of investigated entrepreneurs, types of founded enterprises as well as the strategies designed to create their own cluster of companies. An article of Turkina, Oreshkin, Kali (2013) is dedicated to the empirical analysis of the innovative firms productivity in regional innovation clusters, according to the results of which it has been established that the connection with high-performance firms (in horizontal relations), research institutes and universities located in the cluster help the firms to overcome the negative effects of cluster placement.

In the article of Kozhukhivska, Parubok, Petrenko, Podzihun, Udovenko (2017) there was carried out an analysis and development of methods for assessing the effectiveness of creating regional innovation clusters for dynamic economic development and there were reviewed methods of quantitative evaluation of cluster productivity based on the analysis of the effects of reducing transaction costs, cost of capital, marketing costs, dissemination of innovations and the use of common infrastructure.

While paying tribute to the above-mentioned scientific achievements, it should be noted that there is not enough research aimed at determining the degree of efficiency of the operation of individual enterprises within the innovation cluster. At 
the same time, in the existing works the method of estimating the relationships between the participants of the innovation cluster is not fully reflected and substantiated. Therefore, the purpose of our research is to develop a methodology for assessing the effectiveness of the enterprises interaction in the innovation cluster for further planning of measures to improve its functioning.

Object of the research is a cluster in a market environment, subject of research is organizational and economic relations resulting from the management of an innovation cluster.

In the process of scientific research, the following methods were used: the method of comparison and synthesis - to study the foreign experience of state regulation and support of innovative clusters; econometric method - to develop a methodology for assessing the effectiveness of the enterprises interaction in the innovation cluster; abstract-logical method - to formulate conclusions and implement theoretical generalizations on the typical features of the functioning of innovation clusters; graphic method - for visual presentation of theoretical and analytical material to reflect the main tendencies development of innovative clusters.

The methodology developed in the course of the study should be used in forming the directions of the development strategy of new cluster members, in adjusting the existing strategy to the acting clusters of enterprises and in developing measures aimed at increasing the effectiveness of their interaction.

\section{Research results and discussion}

Innovation cluster is an economic mechanism for increasing the competitiveness of countries which consists of a set of different institutions and subsystems. The main role of the cluster in the country's economy is to reduce uncertainty by establishing a sustainable structure of interaction between enterprises, organizations and people in order to promote the formation of a market system in the country, increase of production efficiency, balance of supply and demand, improvement of the quality of goods and services, creation of scientific and technological innovations, and innovations (Hnatenko, Rubezhanska, 2019).

It should be noted that the high ability of clusters to innovate is due to the following reasons:

- the cluster members can respond more adequately and quickly to the needs of customers at the expense of a wider consumer network than a single manufacturer;

- members of the cluster have access to new technologies used in various areas of economic activity;

- the innovation process involves suppliers and consumers, as well as enterprises of other industries;

- as a result of cooperation between enterprises, the cost of research and development works decreases;

- enterprises of the cluster are under intense competitive pressure which is compounded by a constant comparison of their own business with the work of similar companies. 
In our opinion, an innovation cluster can be defined as an economic system characterized by a certain stability, creating a synergistic effect with the interaction of participants, and includes in its structure a set of enterprises, organizations (production and service organizations, universities, research institutes, engineering centers, inventors of innovations, technologies, market institutions, consumers), located on the same territory, interacting on a contractual basis in order to achieve economic growth.

In this regard, the presence in a country (region) of a significant number of industrial complexes, territories with high scientific and technical potential rich in natural and human resources, geographically localized networks of interrelated companies and organizations creates favorable opportunities for the application of cluster strategy with aiming to increase the competitiveness of the national economy and increase the volume of high-tech industries.

At the same time, the mandatory condition for the formation and functioning of the innovation cluster is the existence of a unified information system supporting the product life cycle which is created at the expense of state budget funds at various levels and is controlled by an authorized body of state administration. In the world practice, in order to facilitate the operation of innovative clusters a number of support tools are successfully used, as shown in Fig. 1. 


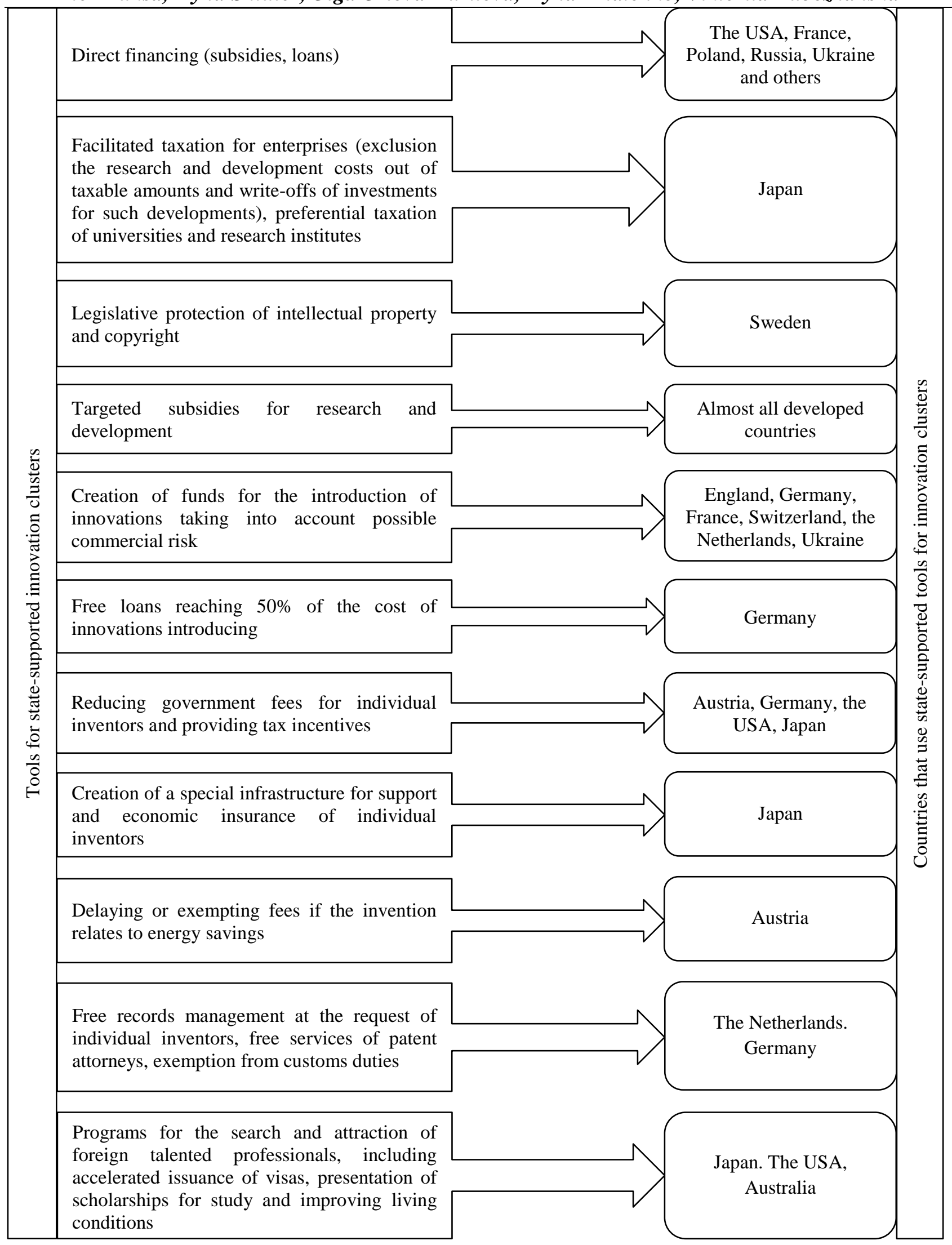

Fig. 1 Instruments of state support for innovative clusters in the countries around the world Source: developed by authors 
However, it should be noted that the effectiveness and feasibility of the tools for supporting innovative clusters abovementioned in Fig. 1 also depend on the characteristic properties that a cluster has, which determine the specificity of its operation. The basic properties of innovative clusters will be considered in more detail.

One of the main system properties of the innovation cluster is the emergence. Enterprises entering the cluster begin to possess new properties that were not inherent to them when conducting a separate entrepreneurial activity since there is an access to scientific developments, to modern equipment, to qualitative resources within reasonable limits. In addition, there is an increase in the level of internal competition and the growth of specialization. Due to innovations in the technological and organizational spheres the productivity of enterprises - participants of the cluster is increased; the formation of new businesses that extend the boundaries of the cluster is encouraged.

Innovation cluster is characterized by the ability to self-organization and selfimprovement on the basis of innovation. The clusters existing in the world economy demonstrate that the cluster structure can rapidly change due to the constant diversity of its elements (non-efficient elements are replaced by effective ones) and is capable of re-developing, adapting to new environmental conditions, new achievements, innovations, inventions, techniques which is a manifestation of the ability to selforganize. Such an adaptation mechanism is characterized by the following elements of self-organization:

- differentiation - the aspiration of the cluster system to the structural and functional diversity of the elements for further adaptation and adjustment to changing environmental conditions. To increase the diversity of elements of the cluster system it is possible to involve not only innovative enterprises, but also financial, leasing, outsourcing, consulting and other organizations. As a result, new structural and functional opportunities for the development and prosperity of the cluster will emerge;

- lability - maintaining the constancy of the cluster structure under variable conditions and functions.

Another important property of any cluster system is its communicative nature. Innovation cluster is constantly undergoing innovative, material and informational exchange with heterogeneous external environment which is a set of economic entities with which innovation, material and information interchange (innovations, products, finances, marketing communications, etc.) are carried out. In addition to the environment, cluster elements interact with subsystems (individual enterprises, institutions that are not cluster elements), and systems of the same level (other innovative clusters).

In addition, the innovation cluster is characterized by the equality of all its elements. The cluster participants interact on a contractual basis without any restrictions on the rights of each other. If the participant is not profitable in the cluster, he can continue his activity independently. 
Also, an innovative cluster, like any system, is characterized by integrity. That is, the influence on any member of the cluster leads to a change in its other participants' state.

In our opinion, the most important property of an innovation cluster is the emergence of a synergistic effect and, therefore, the formation of integrity in the system. This cluster property is influenced by the dynamic economic environment which manifests itself in the sequence of economic processes with certain spatial and temporal characteristics. The dynamic nature of the environment involves the desire for an optimal redistribution of resources necessary for the existence and development of society. Changing the characteristics of the economic environment influences the course of internal processes in the cluster and causes their change, that is, the evolution of the entire cluster system.

Thus, an innovation cluster will be successful and effective only if it has the basic system properties. Namely, the functioning and the interaction of all components of the cluster must result in a synergistic effect and an emergence. In addition, the innovation cluster must constantly grow and develop while creating certain innovative products (services) necessary for its further activities.

In our opinion, the successful functioning of the innovation cluster depends to a large extent on the effectiveness of the interconnections between its participants. We suggest that the effectiveness of the links between enterprises of the innovation cluster is to be estimated by determining the degree of correspondence of the activity of an individual enterprise to the specific functioning of the cluster and the level of the cluster's need for the resources of the enterprise.

In order to determine the correspondence of the activity of an individual enterprise to the specific functioning of the cluster, it is necessary to construct a table that will reflect the need for an individual enterprise in the resources available in the innovation cluster (Table 1). At the same time, the rows of the table show the resources of the cluster, the columns - the number of enterprises-participants of the innovation cluster.

Table 1. An individual enterprise needs for the resources of the innovation cluster

\begin{tabular}{|l|l|c|c|c|c|c|c|}
\hline \multicolumn{2}{|c|}{ Enterprises, $j$} & $E_{1}$ & $E_{2}$ & $\ldots$ & $E_{n}$ & $Q_{i j}$ & $N_{C i}$ \\
\hline \multicolumn{2}{|l|}{ Resources, $i$} & & & & & & \\
\hline 1 & Financial & $d_{11}$ & $d_{21}$ & $\ldots$ & $d_{n 1}$ & $Q_{1 n}$ & $N_{11}+N_{12}+\cdots+N_{1 n}$ \\
\hline 2 & Labor & $d_{12}$ & $d_{22}$ & $\ldots$ & $d_{n 2}$ & $d_{2 n}$ & $N_{21}+N_{22}+\cdots+N_{2 n}$ \\
\hline 3 & Informational & $d_{13}$ & $d_{23}$ & $\ldots$ & $d_{n 3}$ & $d_{3 n}$ & $N_{31}+N_{32}+\cdots+N_{3 n}$ \\
\hline 4 & Material & $d_{14}$ & $d_{24}$ & $\ldots$ & $d_{n 4}$ & $d_{4 n}$ & $N_{41}+N_{42}+\cdots+N_{4 n}$ \\
\hline 5 & Intellectual & $d_{15}$ & $d_{25}$ & $\ldots$ & $d_{n 5}$ & $d_{5 n}$ & $N_{51}+N_{52}+\cdots+N_{5 n}$ \\
\hline
\end{tabular}

Source: developed by authors

In Table 1: $E_{j}$ - the name of $j-t h$ enterprise of the cluster which interacts with the investigated enterprise $(j=1,2, \ldots, n)$.

$d_{i j}$ - the number of agreements for the $i-t h$ resource of the cluster for the period under investigation $(i=1,2, \ldots, 5, j=1,2, \ldots, n)$. 
$Q_{i j}$ - the number of recourses to the $i-t h$ cluster resource for the period under investigation $(i=1,2, \ldots, 5, j=1,2, \ldots, n)$.

$N_{i j}$ - an indicator reflecting the need for the $i-t h$ cluster resource, that is the share of satisfied cluster needs in their total volume $(i=1,2, \ldots, 6, j=1,2, \ldots, n)$ :

$$
N_{i j}=\frac{d_{i j}}{Q_{i j}}
$$

It will be calculated $N_{C i}$ for all enterprises of the innovation cluster on the $i-$ $t h$ resource, which reflects the general necessity for the $i-t h$ resource of all cluster enterprises:

$$
N_{C i}=\sum_{j=1}^{n} N_{i j}
$$

The next step in the proposed assessment of the effectiveness of interconnections in the innovation cluster will be the calculation of a similar indicator which reflects the enterprises need that are part of the cluster in a separate enterprise that was selected for research (Table 2).

Table 2. An innovation cluster need for the resources of an individual enterprise

\begin{tabular}{|c|l|c|c|c|}
\hline \multicolumn{2}{|c|}{ Resources, $i$} & $\begin{array}{c}\text { Number of manufactured goods } \\
\text { (works, services), } P_{i}\end{array}$ & $\begin{array}{c}\text { Number of } \\
\text { appeals, } Q_{i}\end{array}$ & $N_{E i}$ \\
\hline 1 & Financial & $P_{1}$ & $Q_{1}$ & $N_{E 1}$ \\
\hline 2 & Labor & $P_{2}$ & $Q_{2}$ & $N_{E 2}$ \\
\hline 3 & Informational & $P_{3}$ & $Q_{3}$ & $N_{E 3}$ \\
\hline 4 & Material & $P_{4}$ & $Q_{4}$ & $N_{E 4}$ \\
\hline 5 & Intellectual & $P_{5}$ & $Q_{5}$ & $N_{E 5}$ \\
\hline
\end{tabular}

Source: developed by authors

In Table 2: $P_{i}$ - the number of goods (works, services) produced by the enterprise being investigated, using the $i-t h$ resource for the investigated period $(i=1,2, \ldots, 5)$.

$Q_{i}$ - the number of appeals of the investigated enterprise to the $i-t h$ resource in the process of producing goods (works, services) for the period under investigation $(i=1,2, \ldots, 5)$.

$N_{E i}-$ an indicator reflecting the need for the $i-t h$ resource in the enterprise under investigation $(i=1,2, \ldots, 5)$ :

$$
N_{E i}=\frac{P_{i}}{Q_{i}}
$$

In order to determine the effectiveness of the interaction between the individual enterprise and the innovation cluster, as well as to select the direction of the development strategy, it is necessary to rank the indicator of the need for all five 
cluster resources. For each cluster resource the enterprise defines the rank of demand and the rank of the supply, and the cluster, in turn, also exhibits the specified ranks for the resources of the investigated enterprise. At the same time, the following dependence takes place:

for a particular enterprise being investigated - the higher the value for the indicator $N_{E i}$, the lower the value of the demand rank; the higher the value of the $N_{C i}$, the higher greater the rank of the supply;

for enterprises in the cluster - the higher the value for the indicator $N_{C i}$, the lower the value of the rank of demand; the higher the value of the $N_{E i}$, the higher the rank of the supply. Calculated ranks are shown in Table 3.

Table 3. Ranges of demand and supply depending on the need for resources

\begin{tabular}{|c|c|c|}
\hline Value $N_{E i}, N_{C i}$ & Range of demand, $R_{d E i}, R_{d C i}$ & Range of supply, $R_{S E i}, R_{S C i}$ \\
\hline $0,1-0,2$ & 1,0 & 0,2 \\
\hline $0,3-0,4$ & 0,8 & 0,4 \\
\hline $0,5-0,6$ & 0,6 & 0,6 \\
\hline $0,7-0,8$ & 0,4 & 0,8 \\
\hline $0,9-1,0$ & 0,2 & 1,0 \\
\hline
\end{tabular}

Source: developed by authors

$R_{d E i}$ - the rank of demand that is assigned by the investigated enterprise;

$R_{S E i}$ - the rank of the supply that is assigned by the investigated enterprise;

$R_{d C i}$ - the rank of demand that is assigned by the enterprises that are part of the cluster;

$R_{S C i}$ - the rank of the supply that is assigned by the enterprises that are part of the cluster.

To assess an individual investigated company, need for the cluster resources, there will be calculated the indicators of interest of this enterprise, taking into account the demand for resources (4) and taking into account the supply of the innovation cluster of these resources (5):

$$
\begin{aligned}
& I_{d E i}=N_{C i} * R_{d E i} \\
& I_{S C i}=N_{C i} * R_{S E i}
\end{aligned}
$$

In order to assess the need of the enterprises that are part of the innovation cluster for the resources owned by the individual surveyed company, taking into account this enterprise demand for the resources (6) and taking into account the supply of these resources of the enterprise under study (7):

$$
\begin{aligned}
& I_{d C i}=N_{E i} * R_{d C i} \\
& I_{S E i}=N_{E i} * R_{S C i}
\end{aligned}
$$

According to the results of the evaluation four indicators have been obtained, the first two indicators $\left(I_{d E i}, I_{S C i}\right)$ reflect the interests of the individual investigated 
company and the possibilities of their implementation within the cluster, and cluster interest indicators $\left(I_{d C i}, I_{S E i}\right)$ reflect the benefits of interaction of a cluster with a separate enterprise under investigation.

To evaluate the effectiveness of the enterprises interaction in the cluster, it is proposed to construct a matrix in which the values of clusters and enterprises supply will be located on the $\mathrm{Y}$-axis, and the value of demand indicators on the $\mathrm{X}$-axis respectively (Fig. 2).

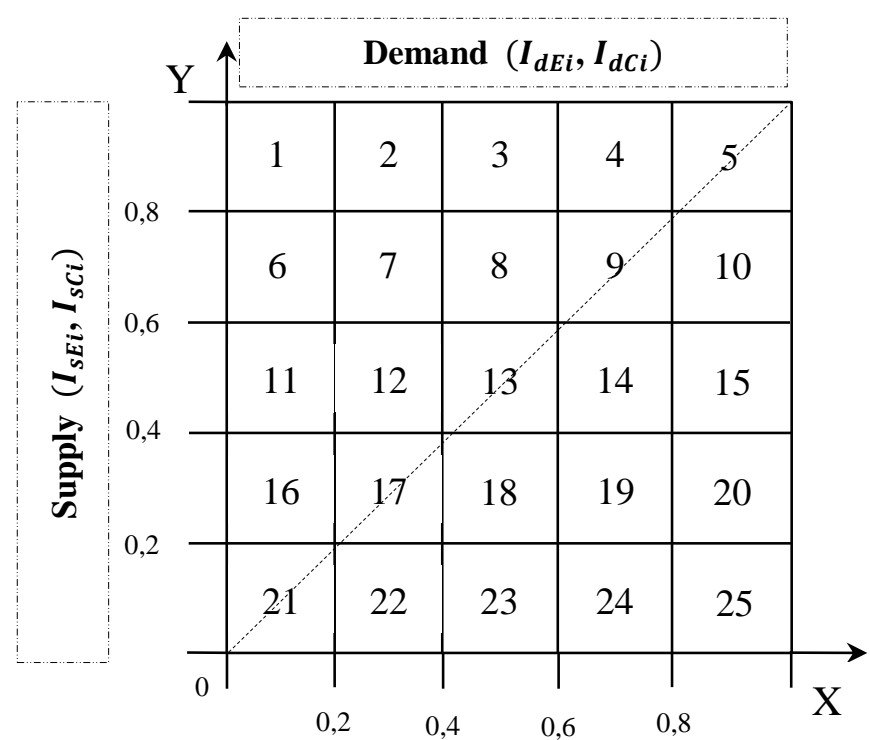

Fig. 2 Matrix "Efficiency of enterprises interaction in the innovation cluster" Source: developed by authors

It should be noted that each square of the matrix, as shown in Fig. 2, has its digital value and characteristics. So, squares 5, 9, 13, 17, 21 reflect the balance of demand and supply for the $i-t h$ resource. However, in this case, squares 17, 21 are characterized by limited demand and supply with mutual interest of a certain enterprise under investigation and the cluster. Under certain conditions, such interaction is beneficial. Squares 5, 9, 13 represent the highest level of efficiency of the interconnections between enterprises of the innovation cluster. The enterprise under investigation is characterized by successful conduct of economic activity, which corresponds to the specifics of the whole cluster, since the $i-t h$ resource of the said enterprise is in demand in the cluster. At the same time, the innovation cluster also has the $i-t h$ resource required for the activity of the aforementioned enterprise.

In squares $4,10,14,8$, demand and supply are close to equilibrium. In real terms a cluster and an individual enterprise (new or that is already a cluster member), interacting favorably on the $i-t h$ resource, most often fall into square data.

Squares 12, 18, 22, and 16 reflect the possible favorable interaction of enterprises in the cluster, but the success of the interconnections will depend on the desire of the participants to yield in conditions of limited demand and supply. 
In squares $3,7,11,15,19,23$ there is no flow of required intensity of the $i-t h$ resource in an enterprise or in an innovation cluster, there is a discrepancy between supply and demand of the $i-t h$ resource in the investigated enterprise or in the cluster.

The intensity of the $i-t h$ stream resource is not sufficient for making managerial decisions in squares 2, 6, 20 24. A particular enterprise or cluster should review its capabilities and requirements. It may be necessary to decide whether to leave the cluster or to develop intensive measures aimed at returning the position of the enterprise. Square 1 indicates the wrong direction of the development strategy and the absence of further prospects for successful interaction in the cluster.

Thus, the proposed matrix reflects the effectiveness of the interaction of a certain enterprise with other enterprises in the innovation cluster for each $i-t h$ resource. As a result of this evaluation, cluster members as well as new enterprises that are planning to become a member of the cluster can choose the direction of the development strategy or adjust the existing strategy and develop measures to increase the effectiveness of the interaction.

\section{Conclusions}

Under conditions of globalization innovative clusters play an important role in the national economy of any country, as they contribute to its development by increasing the interaction of private and public sectors, scientific and educational institutions in the innovation process, which, in turn, raises the country's competitiveness in the global economy.

In the course of the research, a methodology for assessing the effectiveness of interconnections in an innovation cluster was developed by calculating indicators that reflect the interests of each individual cluster participant and their implementation within the cluster, as well as the cluster interest indicators that reflect the benefits of its interaction with each of its own participants. The results of this evaluation should be used in formulating potential directions of the strategy for the development of new cluster participants in adjusting the existing strategy to the acting clusters of enterprises and in developing measures aimed at increasing the effectiveness of their interaction. At the same time, these measures will differ and have specific features depending on the square of the matrix established by the results of the evaluation, but at the same time correspond to the following directions of the overall increase in the efficiency of the innovation cluster functioning, namely: increase of labor productivity, stimulation of innovation development, reduction of the return on assets of cluster enterprises-participants and export activities expanding. 


\section{Management Theory and Studies for Rural Business and Infrastructure Development}

eISSN 2345-0355. 2019. Vol. 41. No. 4: 487-500

Article DOI: https://doi.org/10.15544/mts.2019.39

\section{References}

Enright, M. (2010). Survey on the Characterization of Regional Clusters: Initial Results. Working Paper. https://www.researchgate.net/publication/228599616_Survey_on_the_characterization_of_regional _clusters_initial_results

Feser, E., Renski, H., Goldstein, H. (2008). Clusters and Economic Development Outcomes An Analysis of the Link Between Clustering and Industry Growth // Economic Development Quarterly. Vol.22. No.4: 324-344 - https://doi.org/10.1177/0891242408325419 [01 08 2019]

Foley, H., Freihaut, J., Hallacher, P., Knapp, Ch. (2011). The Greater Philadelphia Innovation Cluster for Energy-Efficient Buildings: A New Model for Public-Private Partnerships // Research-Technology Management. Vol.54. No.6: 42-48. https://doi.org/10.5437/08956308X5406014 [01 08 2019]

Hnatenko, I., Rubezhanska, V. (2019). National labor market: key aspects of state regulation. - Kharkiv: New course. 248 p.

Kozhukhivska, R., Parubok, N., Petrenko, N., Podzihun, S., Udovenko, I. (2017). Methods of assessment of efficiency of creating regional innovative clusters for dynamic development of economics // Investment Management and Financial Innovations. Vol.14. No.3: 302-312. https://doi.org/10.21511/imfi.14(3-2).2017.01 [01 08 2019]

Kukalis, S. (2010). Agglomeration Economies and Firm Performance: The Case of Industry // Clusters Journal of Management. Vol.36. No.2: 453-481. https://doi.org/10.1177/0149206308329964 [01 08 2019]

Kuksa, I., Hnatenko, I., Orlova-Kurilova, O., Moisieieva, N., Rubezhanska, V. (2019). State regulation of innovative employment in the context of innovative entrepreneurship development // Management Theory and Studies for Rural Business and Infrastructure Development. Vol.41. No.2: 228-236. - https://doi.org/10.15544/mts.2019.19 [01 08 2019]

Lindqvist, G., Ketels, Ch., Solvell, O. (2003). The Cluster Initiative Greenbook 2.0.

Stockholm: Ivory Tower Publishers. https://www.hhs.se/contentassets/f51b706e1d644e9fa6c4d232abd09e63/greenbooksep03.pdf [01 08 2019]

Nishimura, J., Okamuro, H. (2011). R\&D productivity and the organization of cluster policy: An empirical evaluation of the Industrial Cluster Project in Japan // The Journal of Technology Transfer. Vol.36. No.2: 117-144. - http://doi.org/10.1007/s10961-009-9148-9 [01 08 2019]

Rauch, A., Doorn, R., Hulsink, W. (2014). A Qualitative Approach to Evidence-Based Entrepreneurship: Theoretical Considerations and an Example Involving Business Clusters // Entrepreneurship Theory and Practice. Vol.38. No.2:333-368. - https://doi.org/10.1111/etap.12093 [01 08 2019]

Rosa, P. (1998). Entrepreneurial Processes of Business Cluster Formation and Growth by 'Habitual' Entrepreneurs // Entrepreneurship Theory and Practice. Vol.22. No.4: 43-61. https://doi.org/10.1177/104225879802200403 [01 08 2019]

Rosenfeld, S. (2005). Industry Clusters: Business Choice, Policy Outcome, or Branding Strategy? // Journal of New Business Ideas and Trends. Vol.3. No.2: 4-13. http://jnbit.org/Images/PDF/Rosenfeld-3-2-2005.pdf [01 08 2019]

Ryneyskaya, L. (2016). The clusters in the modern global economy // Effective economy. Vol.5. - http://www.economy.nayka.com.ua/?op=1\&z=4971 [01 08 2019]

Schumpeter, J. (1976). Capitalism, Socialism, and Democracy. - London: Allen and Unwin (Publishers) Ltd. 460 p. 
Shridharan, L., Manimala, M. (1999). Promoting Industrial Clusters: Review of Experiences in Europe, East Asia and India // The Journal of Entrepreneurship. Vol.8. No.2: 165-193. https://doi.org/10.1177/097135579900800203 [01 08 2019]

Spencer, T. Vinodrai, M. Gertler, Wolfe, D. (2010). Do Clusters Make a Difference? Defining and Assessing their Economic Performance // Regional Studies. Vol.44. No.6: 697-715. http://doi.org/10.1080/00343400903107736 [01 08 2019]

Sternberg, R., Kiese, M., Stockinger, D. (2010). Cluster policies in the US and Germany: varieties of capitalism perspective on two high-tech states // Environment and Planning. C: Government and Policy. Vol.28. No.6: 1063-1082. - http://doi.org/10.1068/c1019b [01 08 2019]

Tessitore, S., Daddi, T., Frey, M. (2012). Eco-innovation and competitiveness in industrial clusters // International Journal of Technology Management. Vol.58. No.1/2: 49-63. https://doi.org/10.1504/IJTM.2012.045788 [01 08 2019]

Turkina, E., Oreshkin, B., Kali, R. (2019). Regional innovation clusters and firm innovation performance: an interactionist approach // Regional Studies. Vol.53. No.8. https://doi.org/10.1080/00343404.2019.1566697 [01 08 2019]

Zaenchkovsky, A. (2018). Prospects of non-ferrous metallurgy enterprises participation in industrial clusters // Economic Annals-XXI. Vol.174. No.11-12: 63-68. https://doi.org/10.21003/ea.V174-10 [01 08 2019] 